SyMPOSIUM ON EVOLUTIONARY APPROACHES TO (COMPARATIVE) LAW:

INTEGRATING THEORETICAL PERSPECTIVES - GHENT, APRIL 2010

\title{
Evolutionary Theories in Law and Economics and Their Use for Comparative Legal Theory
}

GEORG VON WANGENHEIM*

University of Kassel

Evolutionary Law and Economics explains how law evolves in possibly path dependent ways. The theory therefore seems apt to help comparative legal theory in understanding and evaluating legal variation across jurisdictions. This paper reviews evolutionary approaches in Law and Economics to study in a more precise way whether and how different strands of the approach may be useful for the comparative lawyer.

\section{INTRODUCTION}

Comparative studies of legal institutions may be purely descriptive, studying apparently parallel legal rules without comparing them in a strict sense. However, if the intention of comparative legal studies is to contribute to the understanding of national laws or even to develop political suggestions to improve the law, then they need an explicit methodology. The researcher will then take either a functionalist perspective, asking for the real-world problem which a legal rule is intended to solve (Zweigert and Kötz, 1998:\$3, Mattei, 1994) or the researcher will look at the law from a causal perspective, asking what circumstances have led to the current state of the law and-referring back to the functionalist approach-why a legal order has chosen to solve a certain real world problem in the way it has done and not in the way other countries have chosen (Ogus, 1999). It is this latter approach to which evolutionary theories in Law and Economics may contribute.

Writing about evolutionary theories in Law and Economics is always under suspicion of producing just another paper on the superiority, or non-superiority,

\footnotetext{
* I am grateful for the valuable suggestions of the participants of the Seminar on Evolutionary Approaches to Comparative Law at Ghent in April 2010 and an anonymous referee. All remaining errors are mine.
} 
of the common law on efficiency grounds. However, this paper refrains from delving into this discussion. Rather, it aims at reviewing the central arguments of various evolutionary theories which have been used to understand, predict and evaluate legal evolution and which may be useful for comparative legal theory.

Evolutionary theories in Law and Economics often have close links to evolutionary theories in economics proper, but the former remain much narrower than the latter. Both positive economic research on evolving systems and normative economic studies on the evolution of spontaneous orders have enriched similar arguments in Law and Economics. However, evolutionary Law and Economics has never reached the width and depth of the evolutionary economics approaches.

Before presenting the evolutionary theories which are most relevant for comparative legal theory in Sections 3-5, the two central concepts underlying the entire discussion, evolution and comparative legal theory, will be discussed in Section 2. Sections 3 through 5 report the central ideas of the three central evolutionary approaches in Law and Economics - the neo-institutional approach, microeconomic Markov-process models, and the idea of competing jurisdictions. In each of these sections, I will not only present the central ideas of the evolutionary theories, but also discuss their strengths and weaknesses and in particular their use for comparative legal theory.

\section{THE TWO CENTRAL CONCEPTS}

\subsection{WHAT IS EVOLUTION?}

A clear and undisputed definition of evolution and evolutionary theories can hardly be found, as can be seen from discussions in other articles in this issue. In Economics, two broad strands of literature may be distinguished; one based on Universal Darwinism (for example, Hodgson and Knudsen, 2006) and the other on the continuity hypothesis (Witt, 2004).

Universal Darwinism centers its argument on finding analogies to biological evolution and its three core elements - variation, replication and selection. Having found such analogies, adherents of this approach apply and, if necessary adapt, the models established in biology to problems in the economy or - more relevant for the discussion here - in the legal sphere. In part, this strand of evolutionary economics is even stricter, limiting the arguments admissible in evolutionary economics to those models based on the variation, replication and selection of "memes," which are analogous to the genes in biology which carry the relevant information determining the fitness of their carriers to replicate and be selected (phenotypes in biology).

Review of Law \& Economics, (C 2011 by De Gruyter 
Evolutionary Theories in Law and Economics / 739

Followers of the continuity hypothesis are less exclusive in their definition of evolution. All they require for a theory to be evolutionary is that it tackles the emergence of some kind of innovation or novelty and its dissemination within some environment. When studying social or economic phenomena, biological evolution based on genetic variation, replication and selection is relevant only inasmuch as it restricts the possible actions and behavior of the individuals among whom novelty emerges and disseminates.

Universal Darwinism is a powerful tool with which to develop new ideas on, and explanations of, social and economic change, due to its very restrictiveness. Given its narrow frame, it forces the researcher to very clearly define: what varies, where that variation comes from, how replication takes place and which forces drive selection. Once these elements are well defined, a model to predict, or at least understand, the evolution of social phenomena is often quickly at hand. Nevertheless, within the literature sorting itself into evolutionary Law and Economics, Universal Darwinism plays only a minor role. Most approaches only consider legal change and innovation and their dissemination (frequently at least one of these elements is missing); they do not search for the biological analogy. In order not to exclude the larger part of this literature from this review, in the ensuing sections I will therefore be at least as accepting as the adherents of the continuity hypothesis, basically considering all legal-economic literature as evolutionary which the authors themselves, or even others, assign the label of evolutionary Law and Economics.

Legal evolution in such a broad sense takes place in an extremely wide and complex environment. Not only do rules from one legal area interact, and coevolve, with rules from other areas, but also, and perhaps in an even more important way, with non-legal phenomena - both normative (social norms) and positive (technology). Obviously, environments of legal evolution are not confined to one country, but the legal rules of one country co-evolve with the legal rules of other countries. Both the parallel evolution of law within, and the mutual influence of legal rules among, different countries may be fruitful for an explanatory perspective on legal comparison. However, given the complexity of legal evolution within co-evolving environments, models of such evolution will always be partial and will have to concentrate on the most relevant forces driving legal change.

\subsection{WHAT IS COMPARATIVE LEGAL THEORY?}

'Comparative legal theory' obviously has three elements, of which the first two do not need any detailed discussion here, while the last, 'theory,' seems to deserve some closer inspection. Comparative legal theory is legal, when the subjects of comparison are normative rules that are legal in at least one of the

DOI: $10.2202 / 1555-5879.1571$ 
jurisdictions being compared. Comparative legal theory is comparative, when such rules of different jurisdictions - most often geographically defined, but other definitions such as by corporation or other association may be thought of - are studied and compared with respect to their similarities and their differences. Comparative legal theory is theory when the aim of comparison is not only to learn whether rules are different or not, but also to answer the question why they are different or not. The 'why' may be either final or causal.

From the viewpoint of Law and Economics, being a genuinely consequentialist theory of law, the final 'why' seems to suggest itself and, in fact, at least the historically first evolutionary approaches to be presented in the next section will take this perspective to understand why law changes. However, such a functionalist view, sometimes even labeled as functionalist fallacy, is rare in evolutionary theories. They usually explain change by its cause. The very basis of evolutionary theories in biology is the causal explanation of differences in species. Similarly, in evolutionary economics most followers of Universal Darwinism and most followers of the continuity hypothesis reject the functionalist approach and search for causal explanations or descriptions of economic change. The majority of evolutionary approaches in Law and Economics do so too.

As a consequence, most evolutionary theories in Law and Economics may only contribute to answering the causal question of comparative legal theory. Obviously, this implies that evolutionary theories in Law and Economics will rarely help in answering normative questions - the law of which jurisdiction is better? To be sure, it is not impossible to derive normative statements from evolutionary approaches to law, but they will not be definite: if legal evolution takes place in different frameworks in two jurisdictions and one of these frameworks is more apt to result in a normatively preferable situation, then this may serve as a strong argument for the normative superiority of the legal rules observed in this jurisdiction (Cooter, 1994). However, such an argument requires a very profound understanding of legal evolution, its framework, and how the former depends on the latter.

If evolutionary Law and Economics only provides hints but no definite answers to the question that the comparative lawyer is most interested in what legal rule is best? - then why would the evolutionary approach be of any interest to comparative lawyers? The answer can be found in the weakness of other approaches to comparing law from a normative point of view. None of them reaches far enough and covers enough details to deliver unambiguous decisions on the superiority or inferiority of alternative legal rules. As a consequence, evolutionary theories in the realm of Law and Economics, as they will be presented in the remainder of this article, may serve as one argument among others to better understand whether the law in other

\section{Review of Law \& Economics, $\odot 2011$ by De Gruyter}


Evolutionary Theories in Law and Economics / 741

jurisdictions is a solution to a real problem or simply the effect of organized interests leading legal evolution astray, whether the law in a jurisdiction is likely to evolve towards, or away from, efficiency (or whatever the normative criterion may be), and whether legal variation is the result of inferior legislative decisions or a source of desirable competition.

\section{NEO-INSTITUTIONAL APPROACHES: EVOLUTION OF PROPERTY RIGHTS}

Initiated by Harold Demsetz' seminal paper (1967), neo-institutional investigations of legal evolution typically look at specific changes in property rights regimes. The basic idea is closely related to Alchian's (1950) optimistic account of behavioral evolution: societies tend to have institutions which reflect, and are adapted to, the current needs of this society, given their environment and their

preferences. If they did not have such institutions, they would not survive in the long run. Consequently, if the preferences or, more interestingly, the environment of a society change, so will its institutions, legal or not.

Demsetz supports his argument with an empirical example. The Labrador Indians switched from an open access property rights regime to private property when the fur trade made hunting beavers more valuable to each hunter, such that the natural setting could not sustain the radically increased burden resulting from the consequently increased hunting activities. In his reappraisal paper thirty-five years later, Demsetz (2002) subjects his argument to a number of conditions, which must be satisfied to make environmental changes induce optimal institutional adaptations. In particular, he considers as relevant conditions (1) the number and closeness of involved persons, (2) their productivity in solving resource allocation problems, and (3) the complexity of this problem. If they change, most often due to new levels of specialization in production, observable property rights regimes will adapt to better solve the externality problems which become prevalent as a result, so Demsetz (2002) argues. The idea of institutions evolving towards efficiency is also at the heart of the older writings of Douglass North (e.g., 1981), who grounded his account of economic history on this argument.

Independently of whether one wants to label this functionalist Demsetzian approach as truly evolutionary or not, the argument lacks any causal explanation for why the institutions change. There is no discussion of how rules in archaic societies are made, nor is there any hint of legislators' incentives when more complex societies are discussed (mainly in the 2002 paper). Many authors such as Witt (1987), Banner (2002), Eggertson (1990:247-80), and Anderson and Hill $(1975,2002)$ have noted this pitfall of Demsetz' approach.

DOI: $10.2202 / 1555-5879.1571$ 
The idea has been taken up by scholars such as Umbeck (1977a, 1977b), Ellickson (1991, 1994), and Anderson \& Hill $(1975,2002)$, who have argued that societies self-organize and develop property rights when law either does not exist or is not enforced (prominent examples are farmer-ranger conflicts in Shasta County, mining claims during the California gold rush, Maine lobster fishing grounds, and grazing areas of the American Western frontier in the second half of the nineteenth century). More importantly, these authors provide further examples for evolving property rights systems, which all conform with the Demsetzian hypothesis. However, the authors proffer a causal complement to Demsetz' teleological hypothesis: they identify some individuals who find it privately worthwhile to design and enforce property rights against infringing group members or outsiders. Not all examples have remained undisputed. Clay and Wright (2005), for example, challenge Umbeck's observations on mining district codes producing order. They argue that the mining district codes gave equal attention to the rights of claim-jumpers as to claim holders, whence chronic insecurity and litigation resulted.

Most of this literature has a clear normative agenda: to show whether or - more frequently - that property rights which evolve without government's interference are at least as good as property rights designed by governments (or courts). Therefore, they concentrate on historical or very specific contemporary cases, where governments or courts that would otherwise shape the law are absent. While this is most relevant for understanding where the current property rights systems may find their roots, such research does not tell us much about how law evolves in current times in developed countries. However, some writers in the field (notably North (1990), but also Libecap and Lueck (2009)) amend Demsetz' teleological hypothesis by also offering causal explanations (i.e., individual interests in changing law, individual interests resulting in circumventing inefficient law) for the evolution of legal rules within existing states.

When asking whether the neo-institutional approach reviewed in this section may contribute to comparative legal theory, the answer has to be differentiated. In the original, Demsetzian sense of this theory, evolution is driven completely by efficiency. As a consequence, it is only the latter concept, namely efficiency, which may provide an explanation for the differences in legal rules between countries. Thus, if this theory is useful for legal comparisons, then it is not their evolutionary part but the alleged efficiency goal of social evolution.

Taking a closer look at younger versions of the efficiency approach, which also feature individual agents whose interests drive changes in the law, their evaluation concerning its usefulness for comparative legal theory is more optimistic. With their separation of positive and normative theory, the neoinstitutional studies are now able not only to offer an explanation for why

\section{Review of Law \& Economics, $\odot 2011$ by De Gruyter}


institutions evolve towards efficiency, but also to describe conditions under which institutions evolve otherwise. While such conditions will not give the comparative lawyer a clear answer as to which of several observed solutions to the same or similar legal problems is best, they will help him to sort out those observations which are most likely to present a poor solution due to detrimental political influences in the law-making and the law-changing process.

Informal and loosely structured as this approach is, it will still be of great use for legal comparison, because, like Universal Darwinism, it provides a set of permissible and typical arguments to explain legal change and evolution: economic efficiency, economic advantageousness of norms for their adherents, opportunity costs, and transaction costs. Publications within this approach typically dwell, however, so much on idiosyncrasies of particular historical events that one may doubt whether the approach qualifies as a coherent method for comparative legal theory. One of the reasons is that, unlike Universal Darwinism, this approach has no accepted set of models from a partner science which can simply be transferred to the problems at hand.

\section{MICROECONOMIC MODELS OF LEGAL EVOLUTION}

\subsection{DEMAND-SIDE APPROACHES}

In contrast to the functionalist approach, causal explanations of why, how and to where the law evolves have emerged in the literature during the last three and a half decades. This and the following three subsections order the causal explanations by the variables which are most important in driving the evolution. This subsection contains an overview of the models which envisage the evolution as (mainly) demand-side driven, while the next subsection deals with supply-side driven models. I will then take a look at models in which the law co-evolves with social norms, and finally at models which deal with the feedback of law on technology in determining the interests in changing law.

The seminal pair of papers by Paul Rubin (1977) and George Priest (1977) constitute the root of a long history of microeconomic publications on the evolution of the common law, i.e. judge-made law. Rubin's central argument was that legal rules will be challenged in court only if they are inefficient. If rules are efficient, all cases will be settled to avoid litigation costs. The possibility of replacing an inefficient rule by an efficient one, however, allows for enough joint expected future gains from having a better rule to outweigh the litigation costs. As a consequence, so goes Rubin's argument, the common law evolves towards efficiency.

DOI: $10.2202 / 1555-5879.1571$ 
Priest (1977) formalizes the argument as a simple Markov process of the proportion of rules which are efficient, where every rule can be either efficient or inefficient. The transition probabilities between these two possible states are fixed and given by the probabilities that a rule is both litigated in court and replaced by its alternative. In this process, the expected proportion of efficient rules converges to a steady state value which is larger than one-half if courts do not systematically decide against efficiency and inefficient rules are litigated with a higher probability than efficient rules. The steady-state expected proportion of efficient rules is larger than the probability by which a court decides for the efficient rule, as long as inefficient rules are more likely to be litigated than efficient rules. It converges to one if either efficient rules are never litigated, or the judiciary only announces efficient rules.

This formalization of the argument shows its validity only for the cases of sufficiently large joint expected future gains from having a better rule, and under the condition that both parties of the legal conflict dealt with by the legal rule value future gains and losses equally strongly. If only one party cares for the future while the other does not, typically because the former encounters relevant conflicts over and over again while for the latter the conflict is but a unique incident, then the path of legal evolution only depends on the future gains and losses of the former, and therefore legal rules will be challenged not if they are inefficient, but rather when they are to the disadvantage of the party with the stronger interest in the future of the rule.

One could rephrase Priest's argument partly in terms of Universal Darwinism by saying that legal rules replicate whenever they are applied, and that their being challenged in court is the selection mechanism. But the direct replacement by a rule with the opposite efficiency properties fails to have its counterpart in Universal Darwinism as does variation in Priest's theory. This approach is hence evolutionary only in the sense of the continuity hypothesis, and even there doubts may prevail on its evolutionary qualification, since neither is the framework of legal-social evolution determined by previous biological evolution in these theories, nor is any thought spent on the emergence of new rules. Nevertheless, the writings building on Priest's and Rubin's arguments probably form the largest strand of literature usually labeled as evolutionary Law and Economics. It therefore deserves a detailed discussion here.

The argument has been taken up and refined by a large number of later authors, for example by Cooter and Kornhauser (1980), Terrebonne (1981), and Ott and Schäfer (1997), to name only a few. Cooter and Kornhauser delve into the probabilistic aspects of a slightly varied model which, as they show, is a Markov chain model. Assuming a large number of possible alternative legal rules, they demonstrate that equal interests in the future result on average in a

\section{Review of Law \& Economics, () 2011 by De Gruyter}


rather high degree of efficiency, but neither is the most efficient rule the end of all evolution, nor is there eternal stability of any other rule. On the contrary, except for rather restrictive assumptions, all alternative rules will become valid again from time to time, if only for a short time. In other words, the concept of stationary distributions of valid legal rules replaces the concept of the equilibrium rule. Terrebonne (1981) aims at reproducing Rubin's and Priest's results without settlement due to very high transaction costs. His argument, however, fails for cases in which the probability of a plaintiff to sue successfully is very small, although the defendant's costs of care are smaller than its expected reduction in damages. Ott and Schäfer (1997) discuss a Markov-chain model of the evolution of liability standards similar to the one of Cooter and Kornhauser (1980), though with strictly positive transition probabilities only for transitions to more efficient standards. As one would expect from the aforesaid, they show that the judicial process evolves toward the most efficient standard. Miceli (2010) uses a more sophisticated model to derive the same results. Like others, his model allows for asymmetric information rather than the over-optimism of both parties being the reason for settlement failure and for more variation in judges' biases: they may be biased not only for or against efficiency, but also for or against the plaintiff.

It is somewhat surprising that (lawyer-)economists have taken the evolutionary perspective to the law nearly exclusively when considering judge-made law. When it comes to statutory law, most economists rely on static models from Public Choice Theory, either in the Stigler-Peltzman tradition of regulators aiming at satisfying the interests of competing interest groups in the way which is most beneficial to the regulators (Stigler, 1971, Peltzman, 1976), or in the BuchananTullock tradition of rent-seeking. ${ }^{1}$ Given that these approaches stress the influence of particular interest groups not on the evolution but on the content of law, many authors have claimed that the common law, due to its reliance on the evolutionary process of courts making the law, is more efficient than the civil law, in which the negative effects described by the theory of political economy gain full force (e.g., Posner, 1993). A notable early exception to this unequal way of approaching legal change when it is installed by courts or legislators is Gary Becker's (1983) theory of competing pressure groups. He is as optimistic with respect to legislated legal evolution as others are for judge-made law.

Not only do scholars of legislated law rarely adapt an evolutionary approach similar to the Rubin-Priest model (Becker (1983) is an exception), but also adaptation of the standard assumptions of Public Choice models in arguments on common-law evolution is an exception: courts as law-makers are usually

\footnotetext{
${ }^{1}$ See, e.g., Tollison, 1982, for an overview on the early literature.
}

DOI: $10.2202 / 1555-5879.1571$ 
modeled as random decision-makers whose decision probabilities are independent of what the parties spend to influence them. This is obviously in stark contradiction to what is assumed about political law-makers, where the standard assumption is that they are widely susceptible to influence from pressure groups. Goodman (1978) is one of the few who has made the courts' decisions depend on what the parties invest to influence them, and he does so in a way which is very similar to the standard rent-seeking game. Using this idea in a model of judicial precedent, he shows that this may also lead the common law towards efficiency, though only under stronger conditions than those typical for the Rubin-Priest model. In particular, so goes his argument, legal precedents may induce a detrimental path dependency: even if the gains from moving to an efficient rule far outweigh the losses of its opponents, legal precedent may make the probability of a party benefiting from the efficient rule so small that the inefficient precedent will never be challenged in court.

Georgakopoulos (1997) takes a somewhat different but still evolutionary view on the comparison of the efficiency of judge-made versus legislated law. Assuming that the theoretically efficient content of the law changes constantly over time (Georgakopoulos assumes directed Brownian motion), he argues that legislators adapt the law to this perfect content in one big step once the distance between the currently valid law and the ideal exceeds some threshold. The legislator does so independently of whether the currently valid law remains unchanged between these leaps (as would be the case for the archetypal civil law) or adapts constantly, but incompletely, towards the ideal law (as would be the case for archetypal common law). In his paper, Georgakopoulos shows that under these circumstances the average distance between the currently valid law and its ideal is the same for common and civil law if the deterministic part of the change in the theoretically efficient content of the law is linear. It is, however, smaller (larger) for the common law if the deterministic part implies change at an increasing (decreasing) rate. It is interesting to note that this result is independent of how much the change in the common law falls short of the change in the ideal law, as long as it changes at a slower pace than the ideal law.

The argument that the common law is superior to legislated law due to the forces driving its evolution, however, does not find unanimous support. Paul Rubin (1982) was one of the first to caution that any observed efficiency advantage of common law over statutory law might be a historical accident. Hatzis (2002) makes use of an example, vir how legal systems deal with liquidated damages, to prove that the common law may also be inferior in some cases, even when there are no reasons to assume differences in the interests of parties about the valid rules of the future. Fon and Parisi (2003) argue that legal evolution is not so much toward efficiency, but rather toward

\section{Review of Law \& Economics, () 2011 by De Gruyter}


the interests of the typical plaintiff, an argument which is in direct opposition to the results implied by the model of Terrebonne (1981), which predicts evolution towards efficiency unless the law strongly disfavors the plaintiff.

Rubin et al. (2001) and Osborne (2002) do not take as given the degree to which a legal system is driven by judge-made or by legislated law, but rather allow rent-seekers to affect the relative weight of the two sources of law by allocating their activity between the legislator and the courts. While these authors are able to derive equilibria, their insights on the direction of the evolution of law is ambiguous, respectively un-discussed.

\subsection{SUPPLY-SIDE APPROACHES}

Not all scholars of the evolution of the common law have concentrated on the demand side. While demand side approaches are clearly more frequent, the supply side did not remain uninvestigated. Ehrlich and Posner (1974) built their argument on the assumption that, while judges are interested in efficient law, their reputation for not contradicting precedents may substantially curb their private preferences concerning good law. Miceli and Cosgel (1994) extend this idea by arguing that the decision to rule against a precedent is not necessarily a cost to judges. Rather, they argue, it is a decision under risk, since every deviation from an existing precedent may become the foundation for a new precedent and being the founder of a new precedent is extremely valuable for a judge's reputation. Starting from the assumption of a continuous frequency distribution of judges' most preferred legal rules, Miceli and Cosgel find a unique interior equilibrium of the proportion of judges following a precedent, while the other judges depart from whatever precedent exists and replace it by their favorite legal rule. As a consequence, legal evolution will only converge to one legal rule if precedent becomes stronger when being followed for a longer time, so that the equilibrium proportion of judges following precedent grows, and does so fast enough. Whitman (2000) criticizes their argument that every judge will prefer at least some deviation from any prevailing precedent and the underlying assumption of a continuum of legal rules possibly most preferred by a judge. Reducing the set of possible rules to only two rules, he shows that the law may oscillate between these rules, but may also converge to one of these rules if a sufficiently large majority of judges prefers this rule. If no such majority exists, a third rule could serve as a compromise if it is the second-best for all judges and satisfies some further conditions.

Wangenheim $(1993,1995)$ argues along similar lines, with two types of rules but with a different model of judicial decisions to rule against a precedent. $\mathrm{He}$ contrasts the reputation gain from being the founding father of a new precedent to the reputation loss from deviating from precedent. The former is

DOI: $10.2202 / 1555-5879.1571$ 
more likely to prevail if the majority of judges adhering to the precedent is large. The function describing how transition rates between rule types depend on the proportions of judges adjudicating according to the two types of rules thus has the shape of a slanted J: for all but the smallest proportions of followers of a rule, the transition probability is increasing, only for very small proportions of followers of the rule does it become decreasing. As a consequence, Wangenheim's model allows for oscillation of the rules being applied around multiple equilibria, rather than only one equilibrium, as was the case in Miceli and Cosgel's, as well as Whitman's, model. As in the demandside model of Cooter and Kornhauser (1980), oscillations in Wangenheim's and in Whitman's model result from the ergodicity of the underlying Markov chain. Both also suggest combining their supply-side arguments with the classical demand-side arguments described earlier in this section.

Without specific assumptions on judges' preferences to clearly drive the result, supply-side models of the evolution of the common law fail to predict whether the common law evolves towards efficiency or not. As a consequence, the few existing models which join the supply and the demand side (Whitman (2000), for example, goes in this direction towards the end of his paper) do not provide substantially more insights on the direction of the evolution of the law than do simple demand-side models.

Gennaioli and Shleifer (2007) show that judges who dislike erroneous decisions and are individually, but not on average, biased with respect to efficiency, may be expected to improve the common law's efficiency when precedent is strict in the sense that judges may change the legal rule only by further differentiating rules, but not by overruling them. Their argument is based on a model of two dimensions by which legal rules may separate liability from non-liability, and judges who are randomly selected to fix the separation line in the first dimension or the two separation lines in the second dimension within the sets separated by the first dimension.

Ponzetto and Fernandez (2008) derive results similar to those of Georgakopoulos, but from a mainly supply-side driven model, which is far more sophisticated and may also incorporate demand-side models (the Cooter-Kornhauser model is explicitly mentioned), and other special models as well. Sophistication of the model also entails sophistication of the results: The authors describe common law and statutory law by two variables, the binding power of precedent or statute, and the variance of judges' and legislators' preferences. Based on the assumption that the theoretically optimal law changes in one continuous dimension according to a jump process, Ponzetto and Fernandez show that statutory law is best for very volatile societies and common law for stable societies. There is a wide range of parameters which induce mixed forms as optimum.

Review of Law \& Economics, (C 2011 by De Gruyter 
Contrary to the neo-institutional studies on the tradition of Demsetz, the approaches discussed so far in this section are well suited to prove the general possibility of path-dependencies as explanations for persistent legal differences in otherwise very similar jurisdictions. In addition, both demand-side and supply-side approaches show which parameters are most relevant to predict the direction of legal evolution. So, if the comparative lawyer is interested in predicting further evolution of legal systems, or only legal fields with the compared systems, then these theories may be the method to choose. However, one should be aware that these predictions are based on a stochastic model and thus are subject to random influences. In the same vein, these models are useful to make statements on which interests one would expect to be best supported by a law which has evolved within a certain system and thus with certain parameters.

Examples for parameters of legal systems from which current states of the law have evolved and to which the comparative lawyer should pay most attention in order to apply models of the kind described here could be the following. The ability to internalize future effects of legal change (or continuity) and to influence these effects (e.g., the standing of interest groups in courts and in the legislative process) will determine which interest groups are most likely to benefit from the current law. Litigation costs and time horizons of parties not only may affect the influence of different interest groups on legal change, but also the importance of the incentive structures of judges and legislators as they are discussed in the supply-side approaches. The degree to which the law is determined by legislation rather than by court rulings in relation to the speed of social and technological change affects how well-adapted the law tends to be to the socio-technical situation of a society.

Again, using all or any of these parameters will only allow for statements as to which direction the law will have tended, but never on the exact qualities of the law. The basic idea of the evolutionary models described so far is that of predicting general tendencies of the law, not single and separate legal changes. So the comparative lawyer will always have to take a very close look at what idiosyncrasies have determined the political or judicial decisions which steered the law to different states in the jurisdictions under comparison. After making use of statements on the general tendencies of legal evolution derived from the evolutionary approaches described in this section, the comparative lawyer will have to revert to neo-institutional arguments to understand the details of the sources of legal differences across jurisdictions.

DOI: $10.2202 / 1555-5879.1571$ 


\subsection{CO-EvOluTiON OF LAW AND SOCIAL NORMS}

Law is not the only norm system in a jurisdiction and law does not evolve without interaction with the evolution of the other norm system, that is, social norms, nor without interaction with technological evolution. All three systems' evolution is influenced by the state and the change of the respective other systems.

Social norms and their evolution have been widely discussed in economics. The argument on stability of norms in evolutionary settings starts by rather simple situations with only two alternative behaviors, of which one becomes a social norm. ${ }^{2}$ This argument has been extended in particular in relation to experimental game theory, in which the obvious existence of norms had to be explained (Fehr and Schmidt, 1999; Fehr and Fischbacher, 2004; Bolton and Ockenfels, 2000). The indirect evolutionary approach (Güth and Yaari, 1992; Güth 1995; Güth and Ockenfels, 2000), which separates preferences from fitness but lets preferences evolve according to the fitness of the actions they induce for rational agents, suggests itself for modeling the evolution of norms, if they are interpreted as preferences deviating from material payoffs. Dekel et al. (2007) offer very general results on the stability of norms in such settings with various degrees of information on the preferences of other individuals.

It is not in the scope of this paper to discuss these theories in detail. What is of interest here, is how they interact with law and legal evolution, an endeavor rarely undertaken in writings on social norms. The few examples take a clearly one-sided perspective, discussing either how the law shapes the evolution of social norms or how social norms shape the law. Cooter (1994) is an instance of the latter, discussing how the lex mercatoria, a set of rules which enforces and regulates contracts between merchants despite their not being subject to any common jurisdiction, evolved spontaneously, that is, without design or enforcement by governments. Nevertheless, so Cooter argues, judges deduce the law they impose on merchants by deducing their decisions from their observations of these social norms.

Cooter argues that one may expect this set of norms to be efficient because they evolved in a framework which should tend toward efficiency. In a similar vein, Clay (1997) describes merchants in California who traded long before any state was established in the area. Again, the enforcement mechanism of norms, in particular performance of long distance contracts, was punishment by the group of merchants. In this case, however, the institutions securing trade eventually broke down because in-group relationships became weaker due to a

\footnotetext{
2 See, for example, the overview articles by Ostrom (2000) and Elster (1989), as well as the seminal book by Ullman-Margalit (1977).
}

Review of Law \& Economics, () 2011 by De Gruyter 
Evolutionary Theories in Law and Economics / 751

combination of new merchants and a substantial decline in consumer demand due to the Gold Rush.

More has been said on the subject from a normative perspective. Not the least Cooter (1994) himself, who uses the positive description mainly as a starting point for his normative argument that courts should, under certain conditions, draw the rules they use to adjudicate and thereby transform into law from the social norms. The conditions which in his opinion ensure that social norms tend to be efficient are the following: social norms should be generally accepted inside the group, should not serve to extract welfare from outsiders, and should not be the expression of an inefficient evolutionary lock-in. The last condition casts doubt on the practicability of the idea, since it requires that the courts be able to identify inefficient rules, an ability which would make unnecessary reliance on social norms as a guide. Kraus (1997) adds as a condition that the evolutionary process of social norms should be fast enough to cope with technological progress, which it need not be: it might be that technological evolution is so fast that the cultural evolution of social norms cannot keep pace with it. Then social norms will not be efficient. Cooter (1994) was not the first to argue in this direction. Hayek (1973) argues the same, though with weaker conditions.

That social norms influence the change of law has also been widely discussed in the literature on transplanting legal systems or parts thereof to other jurisdictions, the most prominent examples being less developed countries or historical cases (North, 1990). Here the argument goes that social norms do not drive legal change, but instead may substantially hamper it. If transplanted law deviates too much from social norms, then experience shows that the law may not be effective, as most social behavior (often including market behavior) will remain under the guidance and control of social norms rather than the law.

Carbonara and Pasotti (2010) take yet another approach to the interaction between social norms and law. In a model describing the co-evolution of discrimination and struggles to be protected from discrimination, they employ social norms and the law as tools both to discriminate and to protect from discrimination. However, their model is not very explicit on how legal rules are shaped in this process and accounts only for law following social norms, but no reverse influence is modeled.

The reverse influence (that is, the influence that law has on social norms) has also been studied by too few law-and-economics authors to expect anything close to profound knowledge in the field. A prominent starting point for the discussion is Cooter's (1998) article on expressive Law and Economics. He argues that the evolution of social norms may have multiple attractors and that the law may guide social-norm evolution to one or the other. Up to this point, Cooter's argument is not much beyond what Schelling said in his 1978 book.

DOI: $10.2202 / 1555-5879.1571$ 
However, Cooter goes further. Using a model similar to the one developed by Kuran (1989) for the sudden revolutions in Eastern Europe, he shows that a change in a legal rule may in fact express (whence the name of his theory) that enough individuals in a society have come to favor the new rule to make it law. Even if this law is not enforced, this expression of opinions may tip some further individuals' opinions on what social norms they believe are just, which in turn provides new information for yet further individuals who were close to changing their minds on what social norms to adhere to. Like an avalanche, this may trigger more and more individuals to change their minds on social norms so that the new norm may become widely accepted.

Further studies in this direction are needed. In particular, research should overcome the very simple approach of modeling social norms in two-by-two games, since this rarely catches the complexity of legal rules, which typically have to draw borders in a much wider action space. In addition, social norms must be described by more than one dimension: to understand how they work and how they are influenced by the law, researchers should not only consider their content, but also how strongly they are sanctioned by members of the society. Finally, an individual may adopt two different social norms: one for guiding his or her own behavior (then one could talk of internalized norms) and another for sanctioning other individuals' behavior.

Parisi and Wangenheim (2006) show in an interactive opinion formation model with an ordered set of possible social norms that law may not only trigger the evolution of social norms in the same direction as the law goes, but also in the reverse direction. This may particularly occur when legal change diverges too far from social norms and thus triggers hidden or open opposition. They also show that legal strategies such as front-loading the enforcement of legal rules may avoid such a countervailing effect, though possibly only at a high cost. ${ }^{3}$ These are only first steps in widening the range of possible social norms, and the other additional dimensions of social norms are still completely open to research. Such research seems to be particularly promising if one understands that legal rules rarely affect individual behavior directly: hardly anybody knows exactly what the legal rules are. Only when these rules are transformed into social norms as a reflex of perceived legal norms, will the legal norms become effective.

Given the existence of studies of the influence of social norms on the law and of the reverse influence of the law on social norms, one would expect a discussion of feedback loops between the two norm systems. However, there is still a long way to go. Only after understanding more on the evolution of social

\footnotetext{
3 On these strategies against the countervailing effects of social norms on legislation, also see Carbonara et al. (2008a, 2008b).
}

Review of Law \& Economics, (C 2011 by De Gruyter 
norms in all their complexity of wide possible contents and of at least two dimensions (content and degree of sanctioning, perhaps also internalization) would it make sense to tackle the feedback loops.

As long as these feedback loops are not understood, this branch of evolutionary economics should be used for comparative legal theory only with great care. If one cannot exclude that the law affects social norms too, the reverse effect of social norms on the law is tempting as an explanation of differences, but may be misleading. However, if one can, then evolutionary theories on social norms may provide arguments for the ineffectiveness of law or the necessity to have different legal rules for different social-norm situations. Still, these arguments are on a very general basis and rely heavily on probabilistic modeling. They will hence not offer a ready-to-apply explanation for specific cases, but rather offer a pool of abstract arguments which one will have to make specific for every single study of the comparative lawyer.

\subsection{Co-Evolution OF LAW AND TECHNOLOGY}

Insights from joining the demand and supply forces driving the evolution of the law are much larger, however, if one takes into account that evolving law not only alters the constraints on behavior, but also channels innovation (Witt, 1987) and affects individuals' interests in changing the law. With such feedback loops, the evolution of law may lose its clear direction beyond what Cooter and Kornhauser (1980) and Whitman (2000) have attributed to stochasticity in legal evolution. Interestingly enough, none of the few authors who have attempted to deal with such feedback loops has studied the degree of efficiency as an evolving property of the law, but rather they have focused on the degree to which the law regulates and hinders innovation or fights discrimination. Lee (1991), Woeckener (1993), and Wangenheim $(1993,1995)$ study the evolution of how much the law regulates, and how this interacts with the evolution of the innovativeness of entrepreneurs. Lee's approach is very much in the tradition of the standard Lotka-Volterra model, and results in a unique stable equilibrium of the coevolution of regulation and innovativeness. To reach this stability, Lee has to assume that competing entrepreneurs hamper each other's innovativeness - an assumption which is in stark contrast to usual ideas about competition and entrepreneurial innovativeness. Woeckener gives up this restriction and in consequence finds that the equilibrium need not be unique nor stable. Besides

path dependencies resulting from multiple equilibria, attracting limit cycles of oscillating degrees of regulation and innovativeness may emerge from his model. Wangenheim shows an even richer set of possible attractors. Both Woeckener and Wangenheim rely on a micro-foundation for their macroscopic equations of motion. However, Wangenheim's model refers more to the demand and supply

DOI: $10.2202 / 1555-5879.1571$ 
side approaches to legal evolution discussed above than does Woeckener, who relies exclusively on models from political economy.

More of these co-evolutionary analyses would be needed to better understand what affects the evolution of law and how the law in turn affects these very sources of its own evolution. In particular, further research should focus on efficiency as the evolving aspect of law to complement the degree of regulation. Obviously, when law induces technological change, the concept of efficiency has to be adapted, since static efficiency changes when technology changes. Only with such a dynamic concept of efficiency would it be possible to use the evolutionary models described before to study the evolutionary interaction between law and technology. Based on such co-evolutionary models, it might be possible to find a new comparison of the relative efficiency of common and civil law, perhaps building on Georgakopoulos' (1997) model with its exogenously given change of what is efficient.

To judge the validity of all of the models discussed in the previous section, large numbers of case studies or econometric studies would be needed - only a few exist. To be sure, we do not need econometric studies of how efficient the law currently is, or was, at some given point in time, but studies of the change of law, its determinants and its effects. Three examples of such studies are the one by Pistor et al. (2003) who study the change of corporate law, Eckardt (2001) who gives an overview on how German tort law, in particular accident law, co-evolved with various technologies, and Khan (2004) who undertakes a similar endeavor for American patent and copyright law interacting with the evolution of the transportation industry, early telecommunications (telegraphy), and medical technologies.

Again, theories on legal evolution based on microeconomic arguments and shaped in Markov-process models have their generality both as an advantage and as a disadvantage. From the perspective of comparative law, these theories may give the already-mentioned hints on tendencies of legal evolution as a source of legal differences across jurisdictions. But they will fail due to their inherent stochasticity when it comes to the explanation of specific differences in specific fields of law.

All theories reported in this section study the evolution of one jurisdiction on its own, or in interaction with other, non-legal systems. They all neglect co-evolution of interdependent jurisdictions. From a competitive perspective, this will be the subject of the next section. But even if jurisdictions did not compete, their co-evolution by imitation would be most relevant from a comparative lawyer's perspective, since imitation, or more generally, by learning from others' ideas and experiences ("vicarious learning" in terms of Bandura, (1977)) is at the heart of comparative law. In particular, supply-side

\section{Review of Law \& Economics, $\odot 2011$ by De Gruyter}


approaches are able to incorporate legal comparison, and thus co-evolution by vicarious learning, but their models would have to be developed one or two steps further. What is still lacking is an explicit role for comparative lawyers, who are typically not so much found among politicians or judges, ${ }^{4}$ but rather among legal academics. Very few approaches explicitly consider legal academics (an exception is Wangenheim (1995)) and the author of this review is not aware of any evolutionary model in which comparative legal academics play a role.

An extension of the existing models in this direction might add substantial new insight on comparative law and its role for legal evolution. In particular, if one models legal innovation as a (partly) rational activity, information economics could avail the analysis. Legal innovation is information and thus has the properties of a public good. Under-provision of legal innovation thus tends to prevail: not that national law-makers would suffer from a collective-action problem, and thus innovate less because there are others who could imitate, but they probably will also ignore the positive externalities, and thus will not innovate more when there are potential imitators. The degree of under-provision of legal innovation is, of course, an empirical question, but first-sight theoretical arguments suggest that under-provision occurs. A profound discussion of these issues, which is still lacking in the literature, would also have to take into account that imitating foreign legal rules may be constrained by embeddedness of legal rules in their legal framework and the consequent costs of adaptation. ${ }^{5}$

However, endogenizing the comparative law researcher into the model entails a problem which is very general in nature: to what degree is a researcher able to understand and influence a process of which he is himself an elementary part? Obviously, the aim of legal comparison in a specific legal field cannot be to find the optimal law anymore, if this search would be part of the driving forces in legal evolution, and thus the comparative lawyer could be more or less sure that his proposals, even if transformed into national law, are but a temporary step in an ever-ongoing process of legal evolution. One cannot a priori exclude that an erroneous effort by legal comparatists to find the best solution induces the process of legal evolution to take paths which are in some sense (further to be defined) optimal for the society (of the comparatist's home country or of all co-evolving countries?). But a proof of such normative superiority of this selfimage of lawyers still remains open and will probably be so for a long time.

\footnotetext{
${ }^{4}$ Kersch (2006) reports arguments both in favor of and against reference by constitutional courts to foreign countries' courts dealing with similar problems.

${ }^{5}$ I credit the idea of incorporating the comparative legal scholar into economic models of legal evolution to a referee of an earlier version of this article. Obviously, errors in the suggestions to further develop micro-economic models of legal evolution as proffered here are my own faults.
}

DOI: $10.2202 / 1555-5879.1571$ 


\section{COMPETING JURISDICTIONS}

The studies reviewed up to this point investigate single jurisdictions. They become useful in comparative legal studies only by looking at more than one such single evolving jurisdiction. However, these separately evolving jurisdictions rarely are in line with what the comparative lawyer observes: jurisdictions which communicate in many ways. This communication is at the heart of the theory of competing jurisdictions (Mattei and Pulitini, 1991; Ogus, 1999; van den Bergh, 2000).

Tiebout (1956) was the first to describe the interaction between jurisdictions local communities in his case - as a competitive process, which will eventually entail separation of individuals into various communities according to their differential preferences und certain rather restrictive conditions, in particular concerning the mobility of individuals and the absence of externalities. The idea has been formalized in Buchanan's (1965) theory of clubs. In these early approaches, competition between communities or clubs (governed or owned by entrepreneurs) takes place solely by the movement of individuals from one community or club to another. Hirschman (1970) extended the argument to allow for 'voice' as a second mode of influencing the governor's or owner's decisions. While early writings in the field saw the mission of communities in the provision of public goods in general, the content of legal rules became the subject of investigation in the course of refinements of the argument. Oates and Schwab (1988) were the first to combine fiscal federalism with regulatory rules in a formal model. Frey and Eichenberger (1996) later argued that most public goods need not be supplied and financed by regional polities, but instead 'functional overlapping competing jurisdictions (FOCJ)' could fulfill the task. With these extensions, competition between jurisdictions may refer to legal rules and may be driven both by individuals relocating from one jurisdiction to another and by politicians competing for votes from voters in the jurisdiction who compare the policy of their own jurisdiction to that of others (yardstick competition). Obviously, this is a difference between competition among jurisdictions and competition among firms producing private goods, which should not be neglected.

The analogy between competition among jurisdictions and that among firms suggests carrying the distinction between static and dynamic concepts of competition over to inter-jurisdictional competition. The former concentrates on the properties of the (most often unique) equilibrium. Evolution only becomes relevant as a methodology to determine the influence of the institutional framework of competition on the structure and the efficiency properties of the equilibrium. The other approach is more in line with how evolution was defined before - the interaction of emergence and dissemination of novelty. In this approach, the equilibria to which the market would evolve

Review of Law \& Economics, (C 2011 by De Gruyter 
absent any new innovations are of lesser interest. Researchers in this tradition concentrate more on the question of whether the market operates within a framework which allows the prediction that the market process rather than the market outcome will exhibit the desired properties. The following paragraphs will discuss how both approaches to studying the markets and their evolution are applied to competition among jurisdictions, and how they may be useful for comparative legal theory.

Much of the literature interested in the equilibrium of inter-jurisdictional competition refers to specific legal fields and asks whether competition in the various fields leads to efficient or inefficient equilibria, in other words: whether there is a race to the top or a race to the bottom. The most prominent fields of law discussed in this realm are corporate law (e.g., Easterbrook and Fischel, 1996; Romano, 2005), including securities law (Ribstein, 2005; Choi and Guzman, 1998), and regulation (Oates and Schwab, 1988), in particular European regulation and its harmonization (e.g., Ogus, 1999; van den Bergh, 2000).

In this review of evolutionary Law and Economics as a method possibly useful for comparative legal theory, the relevant question is not whether the existing legal rules in these areas are in fact efficient or not, ${ }^{6}$ but rather how inter-jurisdictional competition affects the evolution towards an equilibrium.

Arguments which only allow for one equilibrium rule or legal order towards which an area of law may evolve in all jurisdictions competing under the same conditions offer three explanations for why legal rules may differ across jurisdictions. Either jurisdictions happen to be at different stages of the development towards the same equilibrium, or their preferences differ and so therefore will their legal rules in equilibrium, or they have evolved in different environments of inter-jurisdictional competition, as may, for example, be the case for states in the USA on the one hand and member states of the EU on the other.

In comparative law, the first of these arguments may be relevant. It will imply, however, that the comparative lawyer will have to suggest that the delayed country transplant the equilibrium law already in force in the other country in order to accelerate legal development. Provocative as such a suggestion could be, one would probably have strong reservations about its evolutionary nature. In the same vein, the second argument, legal differences due to different preferences will hardly be deemed evolutionary. If any, then the last argument (different and sufficiently separated competitive environments) could be convincingly labeled as evolutionary. At least for the time being, its use in comparative legal theory would be very limited, because not even for one

\footnotetext{
${ }^{6}$ For answers to this question on empirical-econometric grounds, see for example the pathbreaking paper by LaPorta et al. (1997), or the argument based on a specific rule by Hatzis (2002).
}

DOI: $10.2202 / 1555-5879.1571$ 
environment of inter-jurisdictional competition is there agreement on how different frameworks work - the race-to-the-bottom-race-to-the-top discussion has not been settled for any of the legal fields mentioned previously.

This lack of agreement may be partly because most papers and books in this area are written in purely verbal form. It is interesting to note that nearly all arguments with more complex or numerous equilibria stem from papers with a formal argument. Bar-Gill et al. (2006) show that in the same competitive framework, one jurisdiction may not only adopt, but also enforce, an efficient set of rules (the example is of course Delaware and corporation law), while the other jurisdictions only adopt the efficient set of rules. The background is simple and perhaps not always convincing: Bar-Gill et al. implicitly assume that enforcement is a natural monopoly. Carbonara and Parisi (2009) show that under certain conditions - sufficiently liberal choice-of-law rules and governments that are benevolent towards their constituency - multiple equilibria of the legal evolution emerge, and hence a strong path dependency.

Multiplicity of equilibria and path dependencies are also brought forward by Mattei (1994), though in an informal paper, and based on the positive Coase theorem: If transaction costs within the jurisdictions are small enough, the efficient legal rule is not unique, hence evolution within the jurisdictions may tend towards different equilibria despite any competitive pressure to abandon inefficient rules. Both explanations for the multiplicity of equilibria for the competitive process may be most helpful for the comparative lawyer to understand why law happens to evolve in different directions even in directly competing countries, and why such lock-in effects may occur. He should be aware, though, that all of these arguments are more or less based on probabilistic models, and thus always allow for an evolution away from the equilibrium as well. Normative conclusions can therefore hardly be drawn, as the possibility of stochastic influences forbids inferring from the framework of the inter-jurisdictional competition to the normative desirability of current actual legal change.

The approaches to competing jurisdictions presented so far neglect the occurrence of novelty and restrict their interest to the dissemination of novelty or newly emerging optimal rules. Inasmuch as they do not allow for the possibility of multiple equilibria, their counterparts in economics proper would hardly be called evolutionary. Evolutionary concepts of competition in economics in general, rely heavily on the idea that competition is not only a work-or-fail process to select the best products (or, in our case, rules), but also a process of producing novelty and innovation (Vanberg and Kerber, 1994), or to use Hayek's (1949) words, a process of discovery. Competition in this evolutionary sense is often also called 'dynamic competition.' Such evolutionary concepts of

\section{Review of Law \& Economics, $\odot 2011$ by De Gruyter}


competition have not only been used in Law and Economics in general to study the effects of legal rules on the economic process and its outcomes (though many authors would be reluctant to predict outcomes of the economic process as this would constitute a 'pretense of knowledge' (Hayek, 1975)), but also with respect to competition among jurisdictions.

Dynamic competition in this sense, that is competition which includes innovation, both in the legal and in the economic spheres, may offer another reason for persistent differences between the laws of competing jurisdictions. However, contrary to the approaches discussed before, differences between legal orders never become stable elements of an equilibrium state but are in a constant flux of adaptation to emerging and disseminating novelties. Understanding this process in detail is much harder than understanding it in general. Authors who adhere to this approach to understanding competition in the sphere of goods and services in general tend to describe the workings of the competitive process on a rather abstract level. Very little is, and - due to the very nature of novelty as hitherto unknown information - can, be said about specific properties of goods or services in current markets. Followers of this evolutionary market theory therefore exclusively concentrate on the legal framework within which competition takes place and whether its properties tend to induce desirable outcomes of the process and a desirable form of the process itself.

The same has to be true, of course, for theories of dynamic competition among jurisdictions. Little can be said about the use and potential harm of specific rules, but the framework for inter-jurisdictional competition may have more or less desirable properties. Often, the argument fails to go beyond the claim that the framework of competition matters and much depends on the institutional framework on the meta-level (Vanberg and Kerber, 1994; Heine and Kerber, 2002). Only a few papers take on the burden to develop clear ideas about desirable properties for the framework of dynamic competition (Kerber and Eckardt (2007), for example, compare two frameworks of inter-jurisdictional competition). As long as this is the case, the benefits are limited for this approach to understanding the competition among jurisdictions for attractive legal rules. Inter-jurisdictional competition then may only offer additional arguments (influences from other jurisdictions) within the efforts to reconstruct the evolutionary forces steering the legal situation of a country to its current state. One may speculate that the legal-economic theory of competing jurisdictions could further develop, and thereby provide more benefits for comparative legal theory, if verbal and formal evolutionary approaches to markets for goods and services as they exist in evolutionary economics were adopted. Still, even at their current state, theories of dynamic competition among jurisdictions may provide

DOI: $10.2202 / 1555-5879.1571$ 
normative conclusions for legal comparison; probably the most provocative amongst them being that legal variation among jurisdictions is a value in itself.

If one thinks of legal evolution as a process of dynamic competition, the endogeneity problem mentioned at the end of the Section 4 becomes even more prevalent. Comparative lawyers can only play a part within the evolutionary process and, in addition, the claim to know which observed rule would be best for a country would be a clear pretense of knowledge in the Hayekian sense. Incorporating evolutionary Law and Economics into comparative legal theory thus poses a severe challenge to the role of the comparative lawyer as he sees himself. 7

\section{CONCLUSIONS}

This article has studied the use of evolutionary theories in Law and Economics for comparative legal theory. Neo-institutionalist approaches were shown to provide a bouquet of arguments which may be used in legal comparison to explain the evolution of law and the consequent differences in the state of law across jurisdictions. What is lacking in these approaches is the consistent overarching model of evolution which could be transplanted to legal evolution in the same manner as models of evolution are transplanted from biology to the social sciences and economics in particular.

Microeconomic approaches driven by the demand for, and supply of legal rules, as well as their interactions with social norms and technological evolution, may provide such models, but, being based on Markov processes and thus on stochasticity, these models may only describe and predict expected values of legal change. As a consequence, explanations of specific legal variations cannot be traced back to specific elements of these evolutionary theories in Law and Economics. Obviously, this caveat persists even if one extends the models to allow for co-evolution of jurisdictions partly driven by comparative lawyers' research. Nevertheless, the said microeconomic approaches may still be useful for normative evaluations of differences in the law: If the frameworks of legal evolution in the compared jurisdictions differ, the theory may offer arguments for why the evolution in one or the other will tend towards a more desirable outcome (for example, efficiency). The comparative lawyer should, however, always be aware that these theories can only make statements about tendencies of evolution, not on specific legal changes.

The same caveats apply in an even stronger way to the use of (evolutionary) theories of inter-jurisdictional competition for legal comparison. Here again,

\footnotetext{
${ }^{7}$ Again, credit for this argument is given to the referee, while the usual caveat prevails.
}

Review of Law \& Economics, (C) 2011 by De Gruyter 
Evolutionary Theories in Law and Economics / 761

the theory exists, though still with many unresolved questions, but it may only provide statements on the tendencies of evolution. Only if the comparative lawyer is striving for general theories to explain and evaluate the existence of legal differences across jurisdictions, will evolutionary theories based on microeconomic modeling or competing jurisdictions serve his goals in an unrestricted way. One of the important results of such theories is that the comparative lawyer's search for better legal rules may be doomed to failure: path-dependencies and context embeddedness may prevent the successful transplantation of legal rules providing solutions to common problems in foreign jurisdictions.

\section{References}

Alchian, A. 1950. "Uncertainty, Evolution and Economic Theory," 58 Journal of Political Economy 211-221.

Anderson, T.L., and P.J. Hill. 1975. "The Evolution of Property Rights: A Study of the American West," 18 Journal of Law and Economics 163-179. and . 2002. "Cowboys and Contracts," 31 Journal of Legal Studies S489-S514.

Bandura, A. 1977. Social Learning Theory. Englewood Cliffs: Prentice Hall

Banner, S. 2002. "Transitions Between Property Regimes," 31 Journal of Legal Studies S359-S371.

Bar-Gill, O., M. Barzuza, and L. Bebchuk. 2006. "The Market for Corporate Law," 162 Journal of Institutional and Theoretical Economics 134-160.

Becker, G.S. 1983. "A Theory of Competition among Pressure Groups for Political Influence," 98 Quarterly Journal of Economics 371-400.

Bolton, G.E., and A. Ockenfels. 2000. "ERC: A Theory of Equity, Reciprocity, and Competition," 90 American Economic Review 166-193.

Buchanan, J. 1965. “An Economic Theory of Clubs,” 32 Economica 1-14.

Carbonara, E., and F. Parisi. 2009. "Choice of Law and Legal Evolution: Rethinking the Market for Legal Rules," 139 Public Choice 461-492.

and P. Pasotti. 2010. "Social Dynamics and Minority Protection," 30 International Review of Law and Economics 317-328.

F. Parisi, and G.v. Wangenheim. 2008a. "Lawmakers as Norm Entrepreneurs," 4 Review of Law and Economics 779-799. and 2008b. "Legal Innovation and the Compliance Paradox," 9 Minnesota Journal of Law, Science and Technology 837-860.

Choi, S., and A. Guzman. 1998. "Portable Reciprocity: Rethinking the International Reach of Securities Regulation," 71 Southern California Law Review 903.

Clay, K. 1997. "Trade Without Law: Private-Order Institutions in Mexican California," 13 Journal of Law, Economics and Organization 202-231.

and G. Wright. 2005. "Order Without Law? Property Rights During the California Gold Rush,” 42 Explorations in Economic History 155-183.

DOI: $10.2202 / 1555-5879.1571$ 
Cooter, R.D. 1994. "Structural Adjudication and the New Law Merchant: A Model of Decentralized Law," 14 International Review of Law and Economics 215-231. . 1998. "Expressive Law and Economics," 27 Journal of Legal Studies 585-608. and L. Kornhauser. 1980. "Can Litigation Improve the Law without the Help of Judges?” 9 Journal of Legal Studies 139-163.

Dekel, E., J.C. Ely, and O. Yilankaya. 2007. "Evolution of Preferences," 74 Review of Economic Studies 685-704.

Demsetz, H. 1967. "Toward a Theory of Property Rights," 57 American Economic Review, P\&P 347-359.

. 2002. "Toward a Theory of Property Rights II: The Competition Between Private and Collective Ownership," 31 Journal of Legal Studies S653-S672.

Easterbrook, F.H., and D.R. Fischel. 1996. The Economic Structure of Corporate Law. Cambridge, UK: Cambridge University Press.

Eckardt, M. 2001. Technischer W andel und Rechtsrevolution. Tübingen: Mohr.

Eggertson, T. 1990. Economic Behavior and Institutions. Cambridge University Press.

Ehrlich, I., and R. Posner. 1974. "An Economic Analysis of Legal Rule Making," 3 Journal of Legal Studies 257-286.

Ellickson, R. 1991. Order Without Law: How Neighbors Settle Disputes. Cambridge, Mass.: Harvard University Press. . 1994. "The Aim of Order Without Law," 150 Journal of Institutional and Theoretical Economics 97-100.

Elster, J. 1989. "Social Norms and Economic Theory," 3 Journal of Economic Perspectives 99-117.

Fehr, E., and U. Fischbacher. 2004. "Social Norms and Human Cooperation," 8 Trends in Cognitive Sciences 185-190.

and K.M. Schmidt. 1999. "A Theory of Fairness, Competition and Cooperation," 114 Quarterly Journal of Economics 817-868.

Fon, V., and F. Parisi. 2003. "Litigation and the Evolution of Legal Remedies: A Dynamic Model," 116 Public Choice 419-433.

Frey, B.S., and R. Eichenberger. 1996. "FOCJ: Competitive Governments for Europe," 16 International Review of Law and Economics 315-327.

Gennaioli, N., and A. Shleifer. 2007. "The Evolution of Common Law," 115 Journal of Political Economy 43-68.

Georgakopoulos, N.L. 1997. "Predictability and Legal Evolution," 17 International Review of Law and Economics 475-489.

Goodman, J.C. 1978. "An Economic Theory of the Evolution of Common Law," 7 Journal of Legal Studies 393-406.

Güth, W. 1995. "An Evolutionary Approach to Explaining Cooperative Behavior by Reciprocal Incentives,” 24 International Journal of Game Theory 323-344. and A. Ockenfels. 2000. "Evolutionary Norm Enforcement," 156 Journal of Institutional and Theoretical Economics 335-347. and M. Yaari. 1992. "An Evolutionary Approach to Explain Reciprocal Behavior in a Simple Strategic Game," in U. Witt, ed. Explaining Process and Change - Approaches to Evolutionary Economics. Ann Arbor, MI: University of Michigan Press, 23-34.

Review of Law \& Economics, (C 2011 by De Gruyter 
Hatzis, A. 2002. "Having the Cake and Eating It Too: Efficient Penalty Clauses in Common and Civil Contract Law," 22 Int'l Review of Law and Economics 381-406.

Hayek, F.A.v. 1949. Individualism, and Economic Order. University of Chicago Press. . 1973. Law, Legislation and Liberty, Vol 1: Rules and Order. University of Chicago Press. . 1975. "The Pretence of Knowledge," 77 Swedish Journal of Economics 433-442.

Heine, K., and W. Kerber. 2002. "European Corporate Laws, Regulatory Competition and Path Dependence," 13 European Journal of Law and Economics 47-71.

Hirschman, A.O. 1970. Exit, Voice, and Loyalty. Cambridge University Press.

Hodgson, G.M., and T. Knudsen. 2006. "The Nature and Units of Social Selection," 16 Journal of Evolutionary Economics 477-489.

Kerber, W., and M. Eckardt. 2007. "Policy Learning in Europe: The Open Method of Co-Ordination and Laboratory Federalism," 14 Journal of European Public Policy 227-247.

Kersch, K.I. 2006. "The Supreme Court and International Relations Theory," 69 Albany Law Review 771-799.

Khan, B.Z. 2004. "Technological Innovations and Endogenous Changes in U.S. Legal Institutions, 1790-1920," NBER Working Paper 10346.

Kraus, J.S. 1997. "Legal Design and the Evolution of Commercial Norms," 26 Journal of Legal Studies 377-411.

Kuran, T. 1989. "Sparks and Prairie Fires: A Theory of Unanticipated Political Revolution," 8 Public Choice 235-284.

La Porta, R., F. Lopez-de-Silanes, A. Shleifer, and R. Vishny. 1997. "Legal Determinants of External Finance," 52 Journal of Finance 1131-1150.

Lee, L.W. 1991. "Entrepreneurship and Evolution: Dynamics and Political Economy," 1 Journal of Evolutionary Economics 219-235.

Libecap, G.D., and D. Lueck. 2009. "The Demarcation of Land and the Role of Coordinating Institutions,” NBER Working Paper 14942.

Mattei, U. 1994. "Efficiency in Legal Transplants: An Essay in Comparative Law and Economics," 14 International Review of Law and Economics 3-19. and F. Pulitini. 1991. "A Competitive Model of Legal Rules," in A. Breton, G. Galeotti, P. Salmon, and R. Wintrobe, eds. The Competitive State: Villa Colombella Papers on Competitive Politics. Dordrecht: Kluwer, 207-219.

Miceli, T.J. 2010. "Legal Change and the Social Value of Lawsuits," 30 International Review of Law and Economics 203-208. and M.M. Cosgel. 1994. "Reputation and Judicial Decision-Making," 23 Journal of Economic Behavior and Organization 31-51.

North, D.C. 1981. Structure and Change in Economic History. New York: Norton. . 1990. Institutions, Institutional Change and Economic Performance. Cambridge, UK: Cambridge University Press.

Oates, W.E., and R.M. Schwab. 1988. "Economic Competition Among Jurisdictions: Efficiency Enhancing or Distortion Inducing?” 35 Journal of Public Economics 333-354.

DOI: $10.2202 / 1555-5879.1571$ 
Ogus, A. 1999. "Competition between National Legal Systems: A Contribution of Economic Analysis to Comparative Law," 48 International and Comparative Law Quarterly 405-418.

Osborne, E. 2002. "What's Yours Is Mine: Rent-Seeking and the Common Law," 111 Public Choice 399-415.

Ostrom, E. 2000. "Collective Action and the Evolution of Social Norms," 14 Journal of Economic Perspectives 137-158.

Ott, C., and H.-B. Schäfer. 1997. "Negligence as Untaken Precaution, Limited Information, and Efficient Standard Formation in the Civil Liability System," 17 International Review of Law and Economics 15-29.

Parisi, F., and G. v. Wangenheim. 2006. "Legislation and Countervailing Effects from Social Norms," in C. Schubert and G.v. Wangenheim, eds. Evolution and Design of Institutions. London: Routledge.

Peltzman, S. 1976. "Toward a More General Theory of Regulation," 19 Journal of Law and Economics 211-240.

Pistor, K., Y. Keinan, J. Kleinheisterkamp, and M.D. West. 2003. "Innovation in Corporate Law," 31 Journal of Comparative Economics 676-694.

Ponzetto, G.A.M., and P.A. Fernandez. 2008. "Case Law versus Statute Law: An Evolutionary Comparison," 37 Journal of Legal Studies 379-430.

Posner, Richard A. 1993. "What do Judges Maximize? (The Same Thing Everybody Else Does)," 3 Supreme Court Economic Review 1-41.

Priest, G.L. 1977. "The Common Law Process and the Selection of Efficient Rules," 6 Journal of Legal Studies 65-82.

Ribstein, L.E. 2005. "Cross-Listing and Regulatory Competition," 1 Review of Law and Economics 97-148.

Romano, R. 2005. "Is Regulatory Competition a Problem or Irrelevant for Corporate Governance?" 21 Oxford Review of Economic Policy 212-231.

Rubin, P.H. 1977. "Why Is the Common Law Efficient?” 6 Journal of Legal Studies 51-63. . 1982. "Common Law and Statute Law," 11 Journal of Legal Studies 205-223. , C. Curran, and J.F. Curran. 2001. "Litigation Versus Legislation: Forum Shopping by Rent Seekers," 107 Public Choice 295-310.

Schelling T.C. 1978. Micromotives and Macrobehavior. New York: Norton.

Stigler, G.J. 1971. "The Theory of Economic Regulation," 2 Bell Journal of Economics and Management Science 137-146.

Terrebonne, R.P. 1981. "A Strictly Evolutionary Model of Common Law," 10 Journal of Legal Studies 397-407.

Tiebout, C.M. 1956. "A Pure Theory of Local Expenditures," 64 Journal of Political Economy 416-424.

Tollison, R. 1982. "Rent-Seeking: An Overview," 35 Kyklos 575-602.

Ullman-Margalit, E. 1977. The Emergence of Norms. Oxford: Clarendon Press.

Umbeck, J. 1977a. "The California Gold Rush: A Study of Emerging Property Rights," 14 Explorations in Economic History 197-226. . 1977b. "A Theory of Contract Choice and the California Gold Rush," 20 Journal of Law and Economics 421-437.

Review of Law \& Economics, () 2011 by De Gruyter 
Evolutionary Theories in Law and Economics / 765

van den Bergh, R. 2000. "Towards an Institutional Legal Framework for Regulatory Competition in Europe," 53 Kyklos 435-466.

Vanberg, V., and W. Kerber. 1994. "Institutional Competition among Jurisdictions: An Evolutionary Approach," 5 Constitutional Political Economy 193-219.

Wangenheim, G.v. 1993. "The Evolution of Judge-Made Law," 13 International Review of Law and Economics 381-411. 1995. Die Evolution von Recht. Tübingen: Mohr.

Whitman, D.G. 2000. "Evolution of the Common Law and the Emergence of Compromise," 29 Journal of Legal Studies 753-781.

Witt, U. 1987. "How Transaction Rights are Shaped to Channel Innovativeness," 143 Journal of Institutional and Theoretical Economics 180-195. . 2004. "On the Proper Interpretation of 'Evolution' in Economics and Its Implications for Production Theory," 11 Journal of Economic Methodology 125-146.

Woeckener, B. 1993. "Innovations, Externalities and the State: A Synergetic Approach," 3 Journal of Evolutionary Economics 225-248.

Zweigert, K., and H. Kötz. 1998. Introduction to Comparative Law, $3^{\text {rd }}$ ed. Oxford: Clarendon Press.

DOI: $10.2202 / 1555-5879.1571$ 